\title{
La COVID-19 y sus efectos en la asimetría de las relaciones UE-China: ¿hacia un nuevo paradigma económico?
}

\section{COVID-19 and its Effects on the Asymmetry of the EU-China Relations: towards a New Economic Paradigm?}

\author{
Augusto García-Weil ${ }^{1}$ \\ Universidad de Málaga (España)
}

Recibido: 01-09-20

Aceptado: 03-10-20

\section{Resumen}

La COVID-19 es una pandemia devastadora. El vehículo para su propagación ha sido la misma red de transportes necesaria para la globalización. El objeto de este trabajo es determinar hasta qué punto la presente situación puede provocar una alteración de las cadenas logísticas de valor entre China y la UE, que a su vez implique un aumento de las asimetrías entre ambas partes. Analizaremos si triunfará el offshoring, el reshoring o el nearshoring. Para ello, realizaremos un análisis de ambos actores internacionales y de sus respectivas reacciones a la pandemia, tanto desde el punto de vista idiosincrático, como económico y administrativo.

Palabras-clave: UE-China, COVID-19 y pandemia, coronavirus, asimetrías, globalización y desglobalización, economía, offshoring, reshoring, nearshoring, paradigma.

\footnotetext{
${ }^{1}$ (agweil@gmail.com). Doctorando en la Universidad de Málaga. Entre sus publicaciones cabe destacar: "The Belt and Road Initiative and the cohesion of the European Union", en Revista de Estudios Europeos, N ${ }^{\circ}$ 74, julio-diciembre (2019); "La Unión Europea ante China en la era COVID-19", en eXtoikos - Revista digital para la difusión del conocimiento económico del Instituto Econospérides, Número 23 - 2020; "European Union-China: Two Asymmetrical Weltanschauungs about Human Rights. Remarks on the United States Concept of Human Right", en Transatlantic Studies Network, 20/01 (2020), Vol. 4, No 7 (enero-junio), 2019.

ORCID: https://orcid.org/0000-0002-8458-6832
} 


\begin{abstract}
COVID-19 is a devastating pandemic. The vehicle for its spreading has been the very transport network needed for globalization. The object of this article is to ascertain how far the current situation might unchain an alteration in the logistic chains between China and the EU, which in turn might increase the asymmetries between both sides. We analyze which trend stands a chance to overcome the others: offshoring, reshoring or nearshoring. To this effect, we perform an analysis of both international players and their respective reactions to the pandemic, from the idiosyncratic, economic and administrative perspectives.
\end{abstract}

Key-words: European Union-China, COVID-19 and Pandemic, Coronavirus, Asymmetries, Globalization and Deglobalization, Economy, Offshoring, Reshoring, Nearshoring, Paradigm.

\title{
1. Introducción
}

Nuestra forma de vida depende en gran medida de la globalización, concretamente de las relaciones mercantiles entre la UE y China, que implican el traslado de personas, bienes y capitales de lado a lado del globo terráqueo. Además de todos estos factores, también se desplazan otros no deseables, como es el caso de las especies invasivas y ahora la COVID-19². Este va a ser uno de los aspectos determinantes en la percepción que el mundo va a tener de la globalización.

Desde mediados de los años 90 del pasado siglo hasta la declaración oficial de la pandemia, las relaciones UE-China reflejaban una clara y creciente asimetría a favor de China. La UE y China oficialmente establecieron relaciones diplomáticas en 1975, y firmaron su primer acuerdo comercial en 1978, el mismo año en que China comenzó su política de reforma y apertura. El informe "The EU and China addressing the Systemic challenge", emitido por Business Europe, mantiene que hoy en día, la UE es el principal socio comercial de China, mientras que China es el segundo socio comercial de la UE. Conforme a dicho estudio, el tráfico de mercancías entre ambas partes ascendió a 604,7 billones de euros en 2018, mientras que el tráfico total en servicios ascendió a un total de 80 billones en 2017. Desde 1978 ha aumentado la balanza comercial a favor

\footnotetext{
${ }^{2}$ Iliana Olivié y Manuel Gracia, ¿Elfin de la globalización? Una reflexión sobre los efectos de la crisis del COVID-19 desde el Índice Elcano de Presencia Global”, en Real Instituto Elcano, ARI 43 (2020), 14/04/2020, p. 7, disponible en http://www.realinstitutoelcano.org/wps/wcm/connect/e08d7209-b66d4946-8fe7-c045fc128375/ARI43-2020-Olivie-Gracia-fin-de-la-globalizacion-reflexion-efectoscrisis-COVID-19-Indice-Ecano-de-Presencia-Global.pdf?MOD=AJPERES\&CACHEID=e08d7209b66d-4946-8fe7-c045fc128375, fecha de consulta más reciente: 21/04/2020.
}

Araucaria. Revista Iberoamericana de Filosofia, Política, Humanidades y Relaciones Internacionales, año $22, \mathrm{n}^{\circ} 45$. Tercer cuatrimestre de 2020. Pp. 405-432. ISSN 1575-6823 e-ISSN 2340-2199 https://dx.doi.org/10.12795/araucaria.2020.i45.17 
de China, hasta el punto de que en los años noventa del pasado siglo el saldo ya empezaba a mostrar un claro superávit a favor de dicho país. Concretamente, según el antedicho documento, en 2018 el tráfico de mercancías con China le produjo a la UE un déficit de 185 billones de euros ${ }^{3}$. Mientras, en 2017 (ya que no disponemos estadísticas de 2018) el superávit a favor de la UE fue de 16 billones de euros ${ }^{4}$.

China está introduciendo otro elemento que probablemente a medio plazo altere la situación descrita de la balanza comercial. El gigante asiático está mejorando los niveles educativos, y especialmente la creatividad ${ }^{5}$, algo que a ciencia cierta tendrá efectos sobre este ámbito.

La actual asimetría no solo estriba en el ámbito comercial, sino que también existe asimetría en otros campos, como el jurídico ${ }^{6}$. La asimetría en el campo de las relaciones internacionales se refleja en un aspecto también económico, como es el proyecto chino de la nueva ruta de la seda, oficialmente llamada en su versión inglesa Belt and Road Initiative, BRI, es decir, Iniciativa de la Franja y la Ruta; por su parte, la UE acomete la TRACECA ${ }^{7}$. Por último, también existe asimetría en el aspecto de los derechos humanos ${ }^{8}$. En este artículo nos ceñiremos a la pandemia y a sus previsibles efectos en el factor asimétrico de las relaciones económicas UE-China.

Precisamente, la asimetría ha favorecido a China de manera palmaria en las últimas décadas hasta el brote de la COVID-19, declarado en el gigante asiático el 31 de diciembre de 2020. Sin embargo, hay opiniones en el sentido

${ }^{3}$ Business Europe, "The EU and China addressing the Systemic challenge - A comprehensive EU strategy to rebalance the relationship with China", en Businesseurope, Enero (2020), disponible en https://www.businesseurope.eu/sites/buseur/files/media/reports and studies/2020-01-16 the eu and china - addressing the systemic challenge - full paper.pdf, fecha de consulta más reciente: $01 / \overline{06} / 202 \overline{0}$

${ }^{4}$ Eurostat News Release, 11/2019-16 January 2019 International trade in services, disponible en https://ec.europa.eu/eurostat/documents/2995521/9499935/2-16012019-AP-EN.pdf/3644d7b2-ac7d4cca-810e-afabd3c00640, fecha de consulta más reciente: 16/07/2020.

5 Jennifer Adams y Tanja Sargent, "Curriculum Transformation in China: Trends In Student Perceptions of Classroom Practice and Engagement", Gansu Survey of Children and Families Papers, 2012, pp. 19-20, available at http://repository.upenn.edu/cgi/viewcontent. cgi? article=1032\&context=gansu papers, fecha de consulta más reciente: 17/07/2020.

${ }^{6}$ Julian Ku, "China's Definition of the 'Peaceful Settlement of International Disputes' Leaves Out International Adjudication”, en Opinio Juris, disponible en http://opiniojuris.org/2013/10/15/ obligation-seek-peaceful-settlement-international-disputes-include-international-adjudication/, fecha de consulta más reciente: 18/06/2020. Por ejemplo, según Julian Ku, China tiene una diferente idea del Derecho Internacional.

${ }^{7}$ Frederick Starr y Svante Cornell, "The EU and Central Asia: Developing Transport and Trade",en Analytical Articles, 10/12/2015, disponible en https://www.cacianalyst.org/publications/analyticalarticles/item/13313-the-eu-and-central-asia-developing-transport-and-trade.html, fecha de consulta más reciente: 18/06/2020.

8 Augusto García-Weil, "European Union-China: Two Asymmetrical Weltanschauungs about Human Rights. Remarks on the United States Concept of Human Rights", en Transatlantic Studies Network, 20/01 (2020), p. 3, disponible en http://transatlanticstudiesnetwork.uma.es/?p=4053, fecha de consulta más reciente: 14/04/2020. 
de que el coronavirus, al provenir del "país del centro", perjudica gravemente su imagen, con lo que el país asiático va a perder su posición global ${ }^{9}$. A lo largo de este trabajo, dilucidaremos esta cuestión.

Esta pandemia ha provocado miles de muertos y millones de contagiados. Además, ha frenado el mundo, especialmente las transacciones mercantiles. Según la Organización Mundial del Comercio (OMC):

Se prevé una reducción del comercio mundial en 2020 de entre el 13\% y el 32\% como consecuencia de la perturbación de la actividad económica normal y de la vida causada por la pandemia de COVID-19 en todo el mundo ${ }^{10}$.

La Unión Europea reaccionó tarde a la pandemia pero, a partir de entonces, ha iniciado una acción comprensiva, no solo interna, sino también internacional ${ }^{11}$. Analizaremos este aspecto más adelante.

La crisis suscitada por esta pandemia tendrá efectos duraderos sobre las relaciones UE-China, incluso una vez que la crisis sea superada ${ }^{12}$.

El objeto general de este artículo es determinar si la COVID-19 va a transformar uno de los aspectos esenciales del comercio, esto es, las cadenas logísticas globales de valor, entre la UE y China. En cuanto al objeto específico del trabajo, se trata de analizar si el cambio en las relaciones económicas altera y en qué medida la relación asimétrica que mantienen la UE y China.

El desarrollo del presente artículo comenzará con el estudio de los peculiares efectos de esta pandemia para, a continuación, analizar las consecuencias de la COVID-19 tanto en la UE como en China. Discerniremos entre las tres opciones de fabricación desde un punto de vista geográfico. En primer lugar, de las tres tendencias objeto de nuestro estudio, la más vigorosa de las tres en las últimas décadas, el offshoring o deslocalización, consiste en fabricar fuera del Estado de origen de la empresa en cuestión, por lo general en Asia. En segundo lugar,

9 Mario Esteban, "La crisis del coronavirus y el estatus internacional de China: cuando la geopolítica y la política doméstica no van de la mano", en Comentario Elcano 6/2020, 18 de marzo de 2020, p. 1, disponible en http:/www.realinstitutoelcano.org/wps/wcm/connect/d1b1819d-6d80-43ebb06f-b51b235da1a0/Comentario-Esteban-crisis-coronavirus-estatus-internacional-China-cuandogeopolitica-y-politica-domestica-no-van-de-la-mano.pdf?MOD=AJPERES\&CACHEID=d1b1819d6d80-43eb-b06f-b51b235da1a0, fecha de consulta más reciente: 10/10/2020.

${ }^{10}$ Organización Mundial del Comercio, "Desplome del comercio ante la pandemia de COVID-19, que está perturbando la economía mundial”, 08/04/2020, disponible en https://www.wto.org/spanish/ news s/pres20 s/pr855 s.htm, fecha de consulta más reciente: 18/06/2020.

11 Comisión Europea, Timeline of EU Action, disponible en https://ec.europa.eu/info/livework-travel-eu/health/coronavirus-response/timeline-eu-action_es, fecha de consulta más reciente: 06/07/2020.

12 John Seaman, "Introduction: China as partner, competitor and rival amid Covid-19", [en John Seaman, coord.: Covid-19 and Europe-China Relations A country-level analysis, European Think-tank Network on China - 29/04 (2020)], p. 5, disponible en http://www.realinstitutoelcano. org/wps/wcm/connect/8c964538-388b-4ab0-aa58-a02f16cbd909/ETNC-Special-Report-COVID19-Europe-China-Relations-2020.pdf?MOD=AJPERES\&CACHEID=8c964538-388b-4ab0-aa58a02f16cbd909, fecha de consulta más reciente: 17/06/2020. 
el reshoring o relocalización, es decir, el regreso de las industrias a su país de origen. En último lugar, la fabricación fuera del país de origen, pero más cerca que el mencionado continente asiático, es decir, el nearshoring. Culminaremos con las conclusiones producto del razonamiento antedicho.

Las fuentes de las que nos serviremos para determinar los objetivos reseñados corresponden básicamente a cuatro tipos: el primero y mayoritario son los artículos académicos. Por otra parte, los think tanks especializados en la materia que nos ocupa. También nos detendremos en la información obtenida de los organismos públicos, tanto nacionales, de ambas partes, como internacionales. Además, las fuentes de las empresas privadas también han sido objeto de nuestro estudio. En toda la clasificación antedicha recurrimos tanto a fuentes que tienen su origen tanto en la UE como en China. Por un lado, el cotejo entre las antedichas fuentes, y por otro lado, entre ambas partes, nos permiten obtener una visión objetiva de la cuestión sometida a estudio.

\section{Las divergentes reacciones de la UE y de China ante la COVID-19}

En este apartado analizaremos las respectivas actitudes y actuaciones de la UE y de China ante la pandemia. En primer lugar, veremos las reacciones de las respectivas sociedades ante la pandemia. En segundo lugar, precisaremos el comportamiento de las economías y de las administraciones públicas de ambos actores internacionales.

\subsection{Resiliencia, ventajas eficientes y cohesión}

Una de las cuestiones esenciales para China va a ser su capacidad para controlar la pandemia y esto no ya solo por haber sido el epicentro inicial de la misma, sino también por sus dimensiones, tanto de población como de superficie, que le dan magnitudes continentales. Con la pandemia bajo control podrá empezar a recuperar su economía.

En principio, la COVID-19 sumió a China en una crisis económica con consecuencias mundiales sobre las cadenas de distribución y los mercados. Pero el éxito de dicho país en la lucha contra la pandemia, en términos comparativos, ha suscitado una nueva dinámica, ya que el gigante asiático ha demostrado ser más adaptativo que la mayoría de las economías occidentales. El citado país asiático es la civilización más antigua y resiliente, con una planificación integral a largo plazo $^{13}$. Este será, así pues, otro campo en el que se librará la

13 Kishore Mahbubani, "Has China Won? The Chinese Challenge to American Primacy", en Ambassadors Brief, disponible en https://mahbubani.net/2020/03/31/has-china-won-the-chinesechallenge-to-american-primacy/, fecha de consulta más reciente: 06/07/2020.

Ignacio Ramonet, "Ante lo desconocido - La pandemia y el sistema-mundo", en Le Monde 
disputa por el liderazgo mundial ${ }^{14}$. China ha aprovechado su ventaja en cuanto a la resistencia, adaptabilidad y al dinamismo ${ }^{15}$.

En cuanto a la UE, debería ser más asertiva, a partir de su conocimiento de sí misma, cara a aumentar la conciencia europea y, por ende, la cohesión ${ }^{16} \mathrm{y}$ solventar la ausencia de una voz única ${ }^{17}$. Sin embargo, la UE está cambiando su actitud en estos ámbitos. El Consejo Europeo (CE) ha librado 37.000 millones de euros, dentro de las políticas de cohesión, para hacer frente a las consecuencias de la COVID-19. Por otra parte, el CE promueve el Marco Financiero Plurianual, que deberá desempeñar un papel esencial en la recuperación de la UE. Entre sus facetas se encuentra la de promover la solidaridad..$^{18}$ Además, a la crisis del coronavirus hay que añadir la crisis de los corona-bonos. Alemania y Holanda, entre otros Estados miembro, se opusieron a los corona-bonos, es decir, a mutualizar la deuda pública de los países del sur de la UE. Las circunstancias de los Estados miembro son diversas, así que los respectivos intereses también se mantienen distantes. En un principio, destacó la rapidez de la respuesta de China respecto de la lenta reacción de la UE ${ }^{19}$. El liderazgo de la UE también se ha visto alterado por la pandemia, con considerables consecuencias geopolíticas ${ }^{20}$. Sin embargo, la UE ha reaccionado, lanzando un ambicioso Plan de Recuperación para Europa ${ }^{21}$. Tanto el Parlamento Europeo (dirigido por David Sassoli) como la Comisión Europea (liderada por Ursula von der Leyen) y el Banco Central Europeo (presidido por Christine Lagarde)

Diplomatique, 04/05/2020, disponible en https://www.eldiplo.org/wp-content/uploads/2020/04/ Ramonet-pandemia.pdf, fecha de consulta más reciente: 13/07/2020.

${ }^{14}$ Stefan Schmalz, "Der Corona-Crash in China", en PROKLA 199, 2/06, (2020), p. 355, disponible en https://doi.org/10.32387/prokla.v50i199.1878, fecha de consulta más reciente: 08/06/2020.

${ }^{15}$ Kishore Mahbubani, The New Asian Hemisphere: The Irresistible Shift of Global Power to the East, Washington, PublicAffairs, 2009.

${ }_{16}$ Pol Morillas, "Hay una normalización del papel de China en el mundo", en CIDOB, Cadena Ser - Hoy por hoy - 26/3/2020, disponible en https://www.cidob.org/prensa/pol_morillas hay_una normalizacion del papel de china en el mundo, fecha de consulta más reciente: 10/04/2020.

${ }^{17}$ Augusto García-Weil, "The Belt and Road Initiative and the cohesion of the European Union", en Revista de Estudios Europeos, № 74, julio-diciembre (2019) disponible en http://www.ree-uva.es/ images/numeros/74/2019-74-107-137.pdf, fecha de consulta más reciente: 14/04/2020.

Charles Powell, Ignacio Molina y José Pablo Martínez (coords.), "Una reflexión estratégica en contexto europeo e internacional", Junio 2020, p. 14, disponible en https://especiales. realinstitutoelcano.org/coronavirus/, fecha de consulta más reciente: 08/07/2020.

18 Consejo Europeo, "Report on the comprehensive economic policy response to the COVID-19 pandemic", 09/04/2020, disponible en https://www.consilium.europa.eu/es/press/pressreleases/2020/04/09/report-on-the-comprehensive-economic-policy-response-to-the-covid-19pandemic/, fecha de consulta más reciente: 01/07/2020.

${ }^{19}$ Mario Esteban, op. cit., "La crisis del coronavirus y el estatus internacional de...", p.3.

${ }^{20}$ Miguel Ángel Benedicto, "Los retos de Europa y su futuro tras la pandemia de la COVID-19", en Documento de Opinión 72 (2020), 26/05/2020, p. 14, disponible en http://www.ieee.es/Galerias/ fichero/docs_opinion/2020/DIEEEO72_2020MIGBEN_retosEU.pdf, fecha de consulta más reciente: 09/06/2020.

${ }^{21}$ Comisión Europea, Plan de Recuperación para Europa, disponible en https://ec.europa.eu/info/ live-work-travel-eu/health/coronavirus-response/recovery-plan-europe es, fecha de consulta más reciente: 08/07/2020. 
iniciaron planes de choque con movilizaciones de recursos a niveles inéditos. Por último, el Consejo Europeo (presidido por Charles Michel), aunque más tarde, también respondió ${ }^{2}$. Por otra parte, el Alto Representante de la Unión para Asuntos Exteriores y Política de Seguridad y Vicepresidente de la Comisión Europea (Josep Borrell) ha hecho un llamamiento para la solidaridad mundial, y apoya el desarrollo de un mecanismo europeo de gestión de crisis y un sistema europeo de lucha contra la crisis ${ }^{23}$.

La solidaridad es esencial dentro de la UE, y esto también afecta a la cohesión social europea. De hecho, entre el 17 y el 21/07/2020, tuvo lugar una reunión especial del Consejo Europeo en la que se aprobó el fondo de recuperación europeo. En esencia, el fondo consta del Marco Financiero Plurianual (MFP) y de medidas específicas de recuperación, incardinadas en el "Next Generation EU" (NGEU) que, según establecen las Conclusiones, van unidos. La excepcionalidad de la situación es tal que la UE, en el marco NGEU ha recurrido a la solicitud de préstamos, concretamente por un montante de 750.000 millones de euros, de los cuales 360.000 millones se destinarán a préstamos, y 390.000 millones a gastos, todos ellos a precios de 2018, con el objetivo de responder al colapso económico provocado por la pandemia. Este plan de reconstrucción activa la solidaridad, en especial en cuanto a dos sectores sociales: por una parte, los pensionistas, y por otro lado, los desempleados. En cuanto a los primeros, las pensiones están incluidas en la Rúbrica "Administración Pública Europea". Se prima la solidaridad, pero no solo a corto, sino también a largo plazo, ya que las Conclusiones mencionan la sostenibilidad del sistema de pensiones. Por lo que respecta a los desempleados, están incluidos en el apartado llamado Objetivo "Inversión en crecimiento y empleo" ${ }^{24}$. Este Consejo Europeo no tiene precedente, por la gravedad de la pandemia y de la crisis. Por ello, la UE ha reaccionado correspondiendo con un acuerdo de gran envergadura, con efectos socio-económicos.

Pero el antedicho documento, llamado "Conclusiones", no se refiere exclusivamente a los efectos de la COVID-19. Además de lo antedicho, las Conclusiones, por ejemplo, hacen uso de un instrumento que no trae causa de la pandemia, sino de la globalización: el Fondo Europeo de Adaptación a la Globalización. Se refiere a los trabajadores en paro a causa de la globalización:

${ }^{22}$ Pablo R. Suanzes "Reactivamos Europa-La UE aprende de sus errores y se moviliza como nunca antes frente a la crisis del coronavirus", en El Mundo, 29/06/2020, disponible en https:// www.elmundo.es/internacional/2020/06/29/5ef8c7adfdddffaf 218 b 45 b3.html, fecha de consulta más reciente: 12/07/2020.

${ }^{23}$ Josep Borrell, "Cuatro prioridades para una estrategia global contra la pandemia", en ICEI Papers COVID-19, No 13, 07/04/2020, p. 2, disponible en https://www.ucm.es/icei/file/iceipapercovid13, fecha de consulta más reciente: 12/07/2020.

${ }^{24}$ Secretaría General del Consejo, "Reunión extraordinaria del Consejo Europeo (17, 18, 19, 20 y 21dejuliode2020)-Conclusiones", EUCO 10/20, CO EUR 8 CONCL 4, disponible en https://www. consilium.europa.eu/media/45124/210720-euco-final-conclusions-es.pdf, fecha de consulta más reciente: 25/07/2020.

Araucaria. Revista Iberoamericana de Filosofia, Política, Humanidades y Relaciones Internacionales, año $22, \mathrm{n}^{\circ} 45$. Tercer cuatrimestre de 2020. Pp. 405-432. ISSN 1575-6823 e-ISSN 2340-2199 https://dx.doi.org/10.12795/araucaria.2020.i45.17 
[E]1 Fondo Europeo de Adaptación a la Globalización [es] un instrumento de solidaridad y de auxilio de emergencia que proporciona ayuda puntual a trabajadores despedidos como consecuencia de reestructuraciones derivadas de la globalización, incluidas las causadas por la automatización y la digitalización $[\ldots]^{25}$.

Es llamativo que este documento oficial incluya este fondo dentro de un marco que se supone dedicado a la reconstrucción de Europa tras los efectos de la COVID-19. Quizá se pudiera interpretar que, inconscientemente, se le atribuyan también a la globalización efectos destructivos en cuanto al empleo.

En el antedicho párrafo, las Conclusiones se refieren en especial a los desempleados despedidos por efecto de la automatización y la digitalización. La UE, así pues, reconoce los efectos de la globalización sobre Europa. Es positivo enfrentarse a una de las claves de los cambios mundiales. La UE, así mismo, emprende acciones para incentivar la economía europea y tratar de evitar la destrucción de empleo.

En el apartado "Gastos", la Rúbrica 1 (p. 18 de las Conclusiones) está dedicada al Mercado único, Innovación y Economía Digital. El primer elemento se refiere a la cohesión; el segundo a un aspecto esencial de la economía china: innovar; y por último, una de las claves de la globalización, en la que China es dominante: el ámbito digital. En definitiva, son aspectos que pretenden mejorar la competitividad de las empresas europeas y, por ende, preparar a la UE ante la globalización. Llama la atención el Mecanismo "Conectar Europa", en el que se hace mención a las redes transeuropeas, que producen cuatro beneficios determinantes para el desarrollo de la UE: facilitan las comunicaciones intereuropeas, incentivan la cohesión socio-económica y territorial, promueven una economía social de mercado más competitiva, y por fin, contribuyen a la lucha contra el cambio climático. Así pues, estas redes de comunicación son un buen ejemplo de políticas positivas e integradoras de la UE.

La COVID-19 es un test de capacidad y resistencia de los actores internacionales. La UE, debido a la crisis, está sufriendo dificultades a dos niveles: por un lado, los daños infligidos por el virus en la economía europea $\mathrm{y}$, por otro, las divisiones en el seno de la UE que han quedado al descubierto debido a la crisis. La UE debería superar sus propias inconsistencias internas y reevaluar la jerarquía de los objetivos de las políticas que pretende alcanzar respecto de China ${ }^{26}$.

\footnotetext{
${ }^{25}$ Id, p. 59.

${ }^{26}$ Matthias Hackler, "Rapprochement amid readjustment: how China sees issues and trends in its changing relationship with the EU", en Asia Europe Journal, 28/05/2020, disponible en https:// link.springer.com/content/pdf/10.1007/s10308-020-00580-5.pdf, fecha de consulta más reciente: 20/06/2020.
} 
Entre las consecuencias de la falta de liderazgo en la UE destacó, en un primer momento, el euroescepticismo, debido a la pérdida de credibilidad de las instituciones ${ }^{27}$.

Vivimos en unos tiempos que exigen liderazgo individual, pero sobre todo, liderazgo colectivo, algo por lo que Europa aún no destaca ${ }^{28}$. Dichos aspectos están íntimamente ligados a los respectivos sistemas políticos.

\subsection{Los efectos de la COVID-19 en la economía y la reacción de las Administraciones Públicas}

Hasta el momento, se puede decir que la COVID-19 ha afectado al planeta en el aspecto sanitario, aunque con significativas diferencias, y lo mismo se puede decir del ámbito económico. La clave parece ser que estribará en que en el resultado se constatará en unas asimetrías crecientes y estructurales, con crecimiento de la brecha de la desigualdad en el ámbito nacional e internacional.

Las finanzas chinas se han mostrado muy estables. El país asiático registra considerables flujos de capital en el mercado de bonos y dispone de un mercado de valores sorprendentemente robusto. La COVID-19 marca una nueva dinámica, de la que China podría salir victoriosa ${ }^{29}$. En relación con este aspecto, es significativo el reciente éxito (15/06/2020) de China respecto de la «criptografía cuántica», también conocida como distribución de clave cuántica $(« \mathrm{QKD} »)^{30}$. La constante innovación es uno de los factores impulsores de las asimetrías $^{31}$. Esta pauta le marca a la UE uno de los caminos a seguir para reequilibrar las asimetrías.

La coronacrisis ha provocado una competencia entre el sistema chino estatal de mercado y el capitalismo occidental. La influencia de China podría prosperar en diversas estructuras de poder. Es probable que se produzca una posición de mercado mejorada de empresas tecnológicas chinas. Por otra parte, puede haber avances en cuanto a conseguir establecer el Renminbi (moneda

\footnotetext{
${ }^{27}$ Nicolás Salvoni, "Covid-19 y política internacional: ¿ estamos ante un cambio de paradigma?", en Economía del Desarrollo, Universidad Nacional de Quilmes, p. 1, disponible en http://economia. unq.edu.ar/la-influencia-de-covid-19-en-la-politica-internacional-estamos-ante-un-cambio-deparadigma/, fecha de consulta más reciente: 01/06/2020.

${ }^{28}$ Andrés Ortega, "The Deglobalization Virus?" en The Globalist-Rethinking globalization, 18/03/2020, disponible en https://www.theglobalist.com/coronavirus-covid19-pandemicglobalization-deglobalization-globalism/, fecha de consulta más reciente: 09/06/2020.

${ }^{29}$ Stefan Schmalz, op. cit., p. 360.

30 Juan Yin et al, "Entanglement-based secure quantum cryptography over 1,120 kilometres", en Nature, 15/06/2020, (2020). disponible en https://www.nature.com/articles/s41586-020-2401-y, fecha de consulta más reciente: 18/06/2020.

${ }^{31}$ Mar Llera, "El paradigma chino en el escenario global", en Araucaria. Revista Iberoamericana de Filosofía, Política y Humanidades, año 18, no 35, primer semestre (2016), pp. 249-274, p. 263, disponible en https://revistascientificas.us.es/index.php/araucaria/article/view/2799, fecha de consulta más reciente: 01/06/2020.
} 
china, cuyo acrónimo es RMB) como patrón del comercio internacional ${ }^{32}$. En cuanto a este último aspecto, hemos de tener en cuenta el lanzamiento del e-RMB, es decir, la criptomoneda oficial china ${ }^{33}$. Estos aspectos confirman la posición de China como líder mundial.

Durante el momento álgido de la COVID-19, existía una aparente ventaja de la UE respecto de China. Pero dicha perspectiva, que se percibía hace tan solo unos meses, ha cambiado radicalmente, ya que el epicentro del coronavirus pasó a situarse en la UE; sin embargo, a la fecha de este artículo se sitúa en los EEUU y en Brasil. Se sabe que esta crisis ha perjudicado a la economía china. Los efectos de la pandemia sobre la economía de ciertos Estados miembro de la UE ya están siendo catastróficos. Hay autores que mantienen que, a pesar de las impresiones que se pudieron percibir durante la pandemia, la crisis provocada por ésta perjudicará la posición internacional del gigante asiático ${ }^{34}$. Consideramos que muy probablemente se produzca el efecto contrario. De hecho, gracias a la proyección internacional de dicho país, la dependencia se ha transformado en interdependencia ${ }^{35}$. En esta situación, los actores internacionales compiten entre sí, pero a ninguno le conviene perjudicar a los demás, ya que, en tal caso, se estaría perjudicando a sí mismo.

La balanza de pagos de las grandes potencias es ilustrativa. China ha conseguido llegar a ser una pieza esencial para los actores mundiales, con el resultado de unas potencias occidentales en creciente dependencia del país del centro $^{36}$. Tan significativa es la mencionada situación que, de los tres grandes actores mundiales, es decir, UE, China y EEUU, es el segundo quien dispone del mayor superávit comercial en la balanza comercial ${ }^{37}$.

${ }^{32}$ Stefan Schmalz, op. cit., p. 361.

Julio Martín Fernández Peláez, "China y Estados Unidos en el interregno por la sucesión imperial: ¿surgimiento de una nueva superpotencia o nuevo orden bipolar?", en Academia, disponible en https://www.academia.edu/43408396/China y_Estados_Unidos_en_el_interregno_por_la sucesi $\% \mathrm{C} 3 \% \mathrm{~B} 3 \mathrm{n}$ imperial surgimiento de una nueva superpotencia o nuevo orden bipolar, fecha de consulta más reciente: 08/06/2020.

${ }^{33}$ Forbes México, "China prueba su moneda digital, el e-RMB, con la que planea dar batalla al dólar", 04/05/2020, disponible en https://www.forbes.com.mx/mundo-china-prueba-su-monedadigital-el-e-rmb-con-la-que-planea-dar-batalla-al-dolar/, fecha de consulta más reciente: 19/06/2020.

${ }^{34}$ Esteban, M., "La crisis del coronavirus y el estatus internacional de China: cuando la geopolítica y la política doméstica no van de la mano", en Comentario Elcano 6 (2020), 18/03 (2020), pp. 1-4, p. 1, disponible en http://www.realinstitutoelcano.org/wps/portal/rielcano es/contenido?WCM GLOBAL CONTEXT=/elcano/elcano_es/zonas es/comentario-esteban-crisis-coronavirus-estatusinternacional-china-cuando-geopolitica-y-politica-domestica-no-van-de-la-mano, fecha de consulta más reciente: 10/10/2020.

${ }^{35}$ Mario Esteban, "La evolución de la política exterior China", en Araucaria. Revista Iberoamericana de Filosofía, Política y Humanidades, año 18, no 35, primer semestre (2016), pp. 301-318, p. 302, disponible en https://revistascientificas.us.es/index.php/araucaria/article/view/2677, fecha de consulta más reciente: 01/06/2020.

${ }^{36}$ Mar Llera, op. cit., p. 254.

37 Íd. 
Sin embargo, China depende de la demanda exterior, es decir, que también está condicionada por la interdependencia ${ }^{38}$. Además, es posible que se enfrente a una segunda crisis provocada por la pandemia, debido al descenso radical de la demanda de las economías occidentales respecto de productos de origen chino $^{39}$. China supo superar el mencionado efecto, con ocasión de la crisis de 2008. En aquélla ocasión, el país asiático recurrió a su mercado interno. En esta ocasión, habrá que observar la reacción del país del centro. Quizá intente activar una vez más, como ya hizo entonces, el mercado interno.

A título de ejemplo de un Estado miembro de la UE, en 2020 España cederá una variación porcentual anual de su PIB real de al menos $8 \%$, mientras que China avanzará $1,2 \%$. Las previsiones para 2021 en cuanto a España son de 4,3\%, mientras que para China son de 9,2\%. De momento, todo apunta a que la asimetría entre la UE y China continuará creciendo, a favor de China ${ }^{40}$.

Existen precedentes de la COVID-19, como el SARS, sucedido entre 2002 y 2004; tan solo 12 meses tras el SARS, el PIB de China creció un 9,4\% De hecho, la Organización para la Cooperación y el Desarrollo Económicos (OCDE) prevé una "[d]esaceleración breve de China, donde el PIB cae por debajo del $5 \%$ en 2020 tras el $6,1 \%$ de 2019 , pero se recupera con el $6,4 \%$ en 2021" "2. De momento, según la Banca March, "[en China] los datos de actividad de las grandes empresas, demuestran que la economía ya funciona a ritmos por encima del $95 \%$ de su capacidad" 43 .

En cuanto a la pandemia y sus consecuencias, sobre todo económicas, China le lleva una considerable ventaja a la UE y a los EEUU al menos en el plano temporal, ya que fue en el país asiático donde primero se declaró la COVID-19. Mientras China ya se encuentra en fase de recuperación, Occidente está en plena recesión ${ }^{44}$. A resultas de la pandemia, el PIB de la Eurozona caerá hasta un $8.4 \%{ }^{45}$.

${ }^{38}$ Barbara Loyer y Béatrice Giblin, “¿Qué mundo geopolítico después de 2020?”, en Geopolítica(s). Revista de estudios sobre espacio y poder, 11 (2020), p. 117, disponible en https://revistas.ucm.es/ index.php/GEOP/article/view/69250/4564456553387, fecha de consulta más reciente: 08/06/2020.

39 Stefan Schmalz, op. cit., p. 360.

40 Sincro Business Solutions, "Últimas proyecciones de crecimiento de Perspectivas de la economía mundial", disponible en https://sincro.com.es/blog/actualidad-economica/covid-19-el-fmi-preve-queen-2020-el-pib-de-espana-caera-un-8/, fecha de consulta más reciente: 15/04/2020.

${ }^{41}$ China Briefing, "China Trade Rebound - The Asian Financial Crisis and SARS Impact, Post Coronavirus Implications", disponible en https:/www.china-briefing.com/news/china-coronavirusrebound-op-ed/, fecha de consulta más reciente: 14/02/2020.

${ }^{42}$ Organisation for Economic Co-operation and Development (OECD), Perspectivas económicas provisionales de la OCDE, marzo 2020 - Coronavirus: La economía mundial en riesgo, disponible en http://www.oecd.org/perspectivas-economicas/marzo-2020/, fecha de consulta más reciente: $22 / 04 / 2020$.

43 Banca March, abril 2020, disponible en https://www.bancamarch.es/recursos/doc/ bancamarch/20200108/2020/informe-mensual-de-estrategia-abril-2020-resumen-es.pdf, fecha de consulta más reciente: 15/04/2020.

${ }^{44}$ Stefan Schmalz, op. cit. p. 356.

${ }^{45}$ Warwick McKibbin y Roshen Fernando, "The Global Macroeconomic Impacts of COVID-19: 
Las autoridades chinas tienen una doble preocupación: por una parte, por la posición de China en las cadenas comerciales a nivel mundial y, por otra, por los efectos de la COVID-19 sobre la imagen de China ${ }^{46}$. Son circunstancias como estas las que podrían beneficiar a la UE para relanzarse a medio y largo plazo, por medio del reshoring. Es precisamente en crisis como esta cuando la UE debe demostrar su competitividad.

En cuanto al aspecto de política internacional, ambas partes cooperan en la lucha contra el coronavirus ${ }^{47}$.

La clave reside en determinar si la crisis sanitaria de la COVID-19 se podrá resolver a lo largo del segundo trimestre de 2020, o si se necesitará más tiempo, a lo que se sume un recrudecimiento de la situación financiera. La diferencia entre estas dos posibilidades marcará el ritmo y forma de la recuperación: la primera posibilitará una recuperación en $\mathrm{V}$, mientras que en la segunda, el crecimiento mundial se reducirá a la mitad (es decir, incluso el $1,5 \%)^{48}$. En todo caso, la incertidumbre reina en este panorama, afectando a las medidas a adoptar por organizaciones internacionales del ámbito económico, como el Fondo Monetario Internacional (FMI) o la Organización para la Cooperación y el Desarrollo Económicos (OCDE) ${ }^{49}$.

A raíz de la Gran Reclusión ${ }^{50}$, el hard power no se va a ver esencialmente alterado, pero sí lo va a ser el soft power ${ }^{51}$. Este último va a crecer, como

Seven Scenarios", en CAMA Working Paper, 19 febrero (2020), p. 21, disponible en http://www. sensiblepolicy.com/download/2020/2020WorkingPapers/2020_19 CAMA_COVID19 mcKibbin fernando 0.pdf, fecha de consulta más reciente: 05/06/2020.

${ }^{46}$ Mario Esteban, op. cit., "La crisis del coronavirus y el estatus internacional de...", p. 1.

${ }^{47}$ National Health Commission of the People's Republic of China, "Timeline of China releasing information on COVID-19 and advancing international cooperation", 06/04/2020, disponible en http://en.nhc.gov.cn/2020-04/06/c 78861 5.htm, fecha de consulta más reciente: 07/06/2020.

${ }^{48}$ Federico Steinberg, "Coronavirus: amenaza económica, respuesta política e implicaciones", en Real Instituto Elcano ARI 22 (2020), 12/04/2020, pp. 1-7, p. 1, disponible en http://www. realinstitutoelcano.org/wps/portal/rielcano_es/contenido?WCM_GLOBAL_CONTEXT=/elcano/ elcano es/zonas es/ari22-2020-steinberg-coronavirus-amenaza-economica-respuesta-politica-eimplicaciones, fecha de consulta más reciente: 13/04/2020.

${ }^{49}$ María Demertzis, André Sapir, Simone Tagliapietra y Guntram Wolff, "An effective economic response to the coronavirus in Europe", en Policy Contribution 06 (2020), Bruegel, pp. 1-10, disponible en https://www.bruegel.org/2020/03/economic-response-coronavirus/. fecha de consulta más reciente: 16/04/2020.

${ }^{50}$ Javier Roldán Barbero, "Reflexiones de un internacionalista sobre la pandemia./4. Los derechos individuales y los derechos (y obligaciones) estatales", en Aquiescencia, 26/06/2020, disponible en https://aquiescencia.net/2020/06/26/reflexiones-de-un-internacionalista-sobre-la-pandemia-4-losderechos-individuales-y-los-derechos-y-obligaciones-estatales-por-javier-roldan-barbero/, fecha de consulta más reciente: 09/07/2020.

${ }^{51}$ Carla Oliva, "La política internacional china en los tiempos del COVID-19. Retos ante una coyuntura compleja", pp. 85-86, [en Anabella Busso, coord.: Relaciones Internacionales en tiempos de pandemia, Rosario, Edición para Centro de Investigaciones en Política y Economía Internacional, 2020], disponible en http://rephip.unr.edu.ar/xmlui/bitstream/handle/2133/18304/Busso,\%20A.\%20 -\%20CIPEI $\% 20-\% 20$ RRII\%20en $\% 20$ tiempos $\% 20$ de $\% 20$ pandemia.pdf?sequence $=3$, fecha de consulta más reciente: 09/07/2020.

Joseph Nye, autor de los términos hard power (HP) y soft power (SP), determina que el poder nacional total (NWP, en su acrónimo en inglés) es igual a la suma del hard power y soft power. El 
se aprecia en "las nuevas rutas de la seda" (oficialmente, BRI) o en el 5G desarrollado por Huawei. El 5G, consistente en la red de quinta generación de tecnología móvil, es entre 10 y 20 veces más rápido que el actual $4 \mathrm{G}$, lo que eleva las conexiones móviles a la categoría de instantáneas. Es relevante el hecho de que Ericsson y Nokia hayan reconocido su incapacidad de competir con los costes de producción de Huawei, por lo que están dispuestos a cooperar con dicha empresa china ${ }^{52}$. A este respecto, el Parlamento Europeo, en cuanto a los informes del Organismo de Reguladores Europeos de las Comunicaciones Electrónicas (ORECE), afirma que el tráfico de redes fijas y móviles ha aumentado durante la crisis de la COVID-19. Así pues, alienta a que los países miembro establezcan sus propias redes $5 \mathrm{G}^{53}$. El $5 \mathrm{G}$ es un claro ejemplo de la situación actual en el aspecto industrial y comercial. Tradicionalmente, en Europa se han fabricado productos de alta calidad, pero de precios no tan asequibles a nivel mundial. En una primera fase, desde los años 80 del siglo XX, China fabricaba a precios baratos, pero con el resultado de una limitada calidad. La pauta desarrollada por la industria china en la última década consistía en mantener unos precios acotados, pero en una segunda fase ha elevado considerablemente su calidad. Y el paradigma actual, en una tercera fase, es el resultado de su insistencia en la innovación: el 5G. China ha desarrollado una tecnología de momento exclusiva, lo que le permite poner sus condiciones. Esto tiene consecuencias estratégicas, debido a dos factores: por un lado, se trata de una tecnología de la comunicación y, por otro, es una tecnología exclusiva. Así pues, estamos hablando de un factor con incidencias directas sobre la soberanía de los Estados. Se trata de cambios que van más allá de lo coyuntural, con efectos directamente estructurales. A su vez, ejemplos como este coadyuvan a que China también crezca como potencia ideacional ${ }^{54}$. Son capacidades que se alimentan mutuamente.

El gigante asiático es punta de lanza "en la construcción de redes $5 \mathrm{G}$, en inteligencia artificial, computación cuántica y superordenadores” y, además, "es la fuente de cinco ramas de la economía mundial: farmoquímica, automotriz,

hard power consiste de de la suma del poder militar (M) y el poder económico (E). El soft power es el resultado de la suma del poder político (P) y cultural (C). Por lo tanto, la fórmula es así: $\mathrm{NWP}=\mathrm{HP}+\mathrm{SP}=\mathrm{M}+\mathrm{E}+\mathrm{P}+\mathrm{C}$. Joseph Nye, "Soft Power", en Foreign Policy, No. 80, Otoño, 1990, pp. 153-171, p. 154, Publicado por: Washingtonpost. Newsweek Interactive, LLC, disponible en http:// www.jstor.org/stable/1148580, fecha de consulta más reciente: 19/03/2017.

52 Santiago Armesilla, "De la Peste Negra al Coronavirus: el Resurgimiento de China en la Segunda Guerra Fría”, en La Razón Comunista, 11/06/2020, p. 8, disponible en https://www.larazoncomunista. com/post/4-2-de-la-peste-negra-al-coronavirus-el-resurgimiento-de-china-en-la-segunda-guerrafr\%C3\%ADa, fecha de consulta más reciente: 12/07/2020.

${ }_{53}$ Parlamento Europeo, Propuesta de Resolución, Documento de sesión B9-0149/2020, 14.4.2020, p. 23, disponible en https://www.europarl.europa.eu/doceo/document/B-9-2020-0149 ES.pdf, fecha de consulta más reciente: 01/09/2020.

${ }^{54}$ Pol Morillas, op. cit.

Araucaria. Revista Iberoamericana de Filosofí, Política, Humanidades y Relaciones Internacionales, año $22, \mathrm{n}^{\circ} 45$. Tercer cuatrimestre de 2020. Pp. 405-432. ISSN 1575-6823 e-ISSN 2340-2199 https://dx.doi.org/10.12795/araucaria.2020.145.17 
aeronáutica, electrónica y telecomunicaciones" ${ }^{\prime 55}$.

Las autoridades chinas han ordenado una prohibición inmediata y absoluta del comercio y consumo de todo tipo de animales salvajes ${ }^{56}$. Concretamente, el Ministerio de Agricultura y Asuntos Rurales de China ha publicado la lista de animales aptos para el consumo humano o que son adecuados para otros fines comerciales. Se trata de 33 especies de ganado y de aves. El fin es conseguir el cumplimiento de la prohibición del comercio ilegal y el consumo de animales salvajes $^{57}$. Esta iniciativa es imprescindible. Tiene un doble efecto: por una parte, por la lucha no solo contra esta pandemia, sino también contra otras potenciales. Por otra, por fin debe ponerse coto a la extinción de numerosas especies salvajes. Esta acción habría de mantenerse de forma coordinada a nivel planetario.

\section{3. ¿China seguirá siendo el proveedor principal de la UE?}

Como hemos analizado, la COVID-19 ha sido contundente en diversos ámbitos. Pero aún hemos de determinar qué efectos va a tener esta situación sobre la geoestrategia, y sobre las relaciones UE-China.

Se puede concretar que la COVID-19 es un hito histórico. Y también es palmario que ha provocado no ya un cambio de la geoestrategia, sino una aceleración de los cambios que se venían produciendo, incluyendo los comerciales. La pandemia ha cambiado nuestro mundo, y no hay marcha atrás. Entre otros efectos, se van a producir repercusiones sobre las cadenas de suministros, focalizadas hasta ahora en el continente asiático ${ }^{58}$.

Ser el origen de la COVID-19 podría, según algunos autores, acarrearle consecuencias a China ${ }^{59}$. En esta coyuntura se nos plantea una cuestión esencial respecto de las cadenas logísticas globales de valor: cara a la UE ¿cabe un

55 Raúl Zibechi, "A las puertas de un nuevo orden mundial" [en Néstor Borri, coord.: Sopa de Wuhan-Pensamiento contemporáneo en tiempos de pandemias, Editorial ASPO (Aislamiento Social Preventivo y Obligatorio), 2020], pp. 115-116, disponible en https://repositorio.uca.edu.ar/ handle/123456789/10038, fecha de consulta más reciente: 12/07/2020.

${ }^{56}$ International Trade Centre (ITC) Market Access Map, COVID-19 Temporary Trade Measures, Temporary trade measures enacted by government authorities in relation to COVID-19 pandemic rapidly spreading across the world, disponible en https://www.macmap.org/covid19, fecha de consulta más reciente: 16/04/2020.

${ }^{57}$ Ministerio de Agricultura y Asuntos Rurales, Gobierno de España, "China publica la lista de animales para consumo humano-Con el objetivo de detener las ventas ilegales de animales salvajes", 04/06/2020, disponible en https://www.mapa.gob.es/images/es/ bne45028chinaal-ga-medprod tcm30-539726.pdf, fecha de consulta más reciente: 09/07/2020.

58 Javier Rosado, "Retos y desafíos de la nueva normalidad", en El Financiero-Economía, Mercados y Negocios en alianza con Bloomberg, 28/05/2020, disponible en https://www.elfinanciero. com.mx/opinion/colaborador-invitado/retos-y-desafios-de-la-nueva-normalidad, fecha de última consulta: 01/06/2020.

59 Mario Esteban, op. cit., "La crisis del coronavirus y el estatus internacional de...", p. 1. 
proveedor alternativo a China? En principio, habría tres opciones: offshoring, reshoring y nearshoring ${ }^{60}$.

Muchos de los países que en las últimas décadas emprendieron el offshoring, se van a decidir por la desglobalización, es decir por el reshoring, pero con limitaciones. Una desvinculación total China-EEUU no es solo improbable sino imposible ${ }^{61}$. Se puede hacer una analogía de lo antedicho respecto de UE-China. Precisamente en estos sectores, como la alta tecnología, concurren cuatro circunstancias: en primer lugar, son estratégicos; en segundo lugar, la UE no tiene una posición preponderante en los mismos; en tercer lugar, China sí es una potencia en este campo; en cuarto y último lugar, como demostramos a lo largo de este artículo, a raíz de la COVID-19, podría disminuir la globalización física, pero a ciencia cierta crece la globalización digital, debido al tráfico de datos a nivel mundial, y es este precisamente otro sector estratégico. En definitiva, la consecuencia de este razonamiento es el crecimiento de la asimetría a favor de China también en este campo.

Una relocalización industrial y de cadenas de suministros a gran escala parece improbable, pero en última instancia, las posibilidades dependen de las respectivas capacidades de cooperación. En todo caso, la pandemia global se ha declarado en un momento particularmente delicado, ya que la sucesión en el liderato europeo ha tenido lugar en un momento de ajuste del bloque europeo con China ${ }^{62}$.

Tras el análisis de las tres mencionadas opciones, realizamos una reflexión conjunta sobre la nueva singladura de la localización industrial.

\subsection{Offshoring}

El offshoring consiste en la deslocalización. Según Vicente Pardo, África subsahariana, Europa emergente, Sudeste Asiático e Iberoamérica son varios de los destinos para los procesos industriales más rutinarios y de menos valor agregado ${ }^{63}$. Pero resta por saber si también estarán capacitados para competir con China como proveedores de la UE. Aún es pronto para concretar esta cuestión. Pero sí se puede señalar que las citadas regiones son zonas de actuación preferente de China. De hecho, por gran parte de ellas transita la BRI.

60 Vicente Pardo, "Offshoring, reshoring y nearshoring: Tres hipótesis para un nuevo orden productivo global post-COVID19”, en RANKIA, 07/04/2020, disponible en https://www.rankia.com/ blog/finanzas-exoticas/4557267-offshoring-reshoring-nearshoring-tres-hipotesis-para-nuevo-ordenproductivo-global-post-covid19, fecha de consulta más reciente: 16/04/2020.

${ }^{61}$ Jean-Pierre Cabestan, "China's Battle with Coronavirus: Possible Geopolitical Gains and Real Challenges", en Al Jazeera Centre for Studies Report, 19/04/ (2020), p. 16, disponible en https:// studies.aljazeera.net/sites/default/files/articles/documents/2020-04/China $\%$ E2\%80\%99s $\% 20$ Battle $\% 20$ with $\% 20$ Coronavirus $\% 20$ Possible $\% 20$ Geopolitical $\% 20$ Gains $\% 20$ and $\% 20$ Real $\% 20$ Challenges.pdf, fecha de consulta más reciente: 03/06/2020.

${ }^{62}$ Matthias Hackler, op. cit.

63 Vicente Pardo, op. cit. 
Dicho país asiático viene siendo uno de los destinos preferentes para aquellas empresas europeas con interés en desarrollarse via offshoring, a pesar de ciertos aspectos a tener en cuenta ${ }^{64}$. Sin embargo, no son pocas las opiniones en el sentido de que la COVID-19 incrementará la tendencia desglobalizadora iniciada antes de la pandemia. Las empresas analizan la incertidumbre que implica la lejana situación de los proveedores ${ }^{65}$. Conforme al Índice Elcano de Presencia Global, la globalización no se ha tornado en desglobalización, si bien es cierto que ha disminuido su ritmo de crecimiento, proceso que comenzó al principio de la década de 2010, aunque no se contrajo más que en dos años (un $-0,7 \%$ en 2014 y un $-1,4 \%$ en 2015 ) y se recuperaba antes de la crisis pandémica ${ }^{66}$.

Además, un número creciente de cadenas logísticas se están anquilosando o estancando, en mucha mayor medida de lo que ocurrió a raíz de la crisis de 2008, y esto es debido a que dichas cadenas son hoy mucho más complejas de lo que eran entonces ${ }^{67}$.

La globalización ha aumentado la capacidad de compra del consumidor, gracias a la producción a gran escala y a la especialización. Establecer cadenas de valor menos sometidas a la fragmentación y, por lo tanto, menos vulnerables ante factores de perturbación, al mismo tiempo implicaría un aumento de precio, que sería repercutido al consumidor ${ }^{68}$. Además, los países en desarrollo dependen en gran medida de la globalización, aunque sus condiciones socioeconómicas sean mejorables.

Por su parte, empresas chinas favorecen la deslocalización de sus propios centros de producción ${ }^{69}$.

\subsection{Reshoring}

El reshoring o relocalización, es una posibilidad que se venía desarrollando ya antes de la pandemia. Consideramos que, tras la COVID-19,

${ }^{64}$ Cecilia Johansson y Elisabeth Reischl, Offshoring to China-A case study of an SMEs offshoring to China, Baltic Business School, University of Kalmar, 2009, p. 105, disponible en http://www. diva-portal.org/smash/get/diva2:222631/FULLTEXT01.pdfElisabeth, fecha de consulta más reciente: 18/04/2020.

${ }^{65}$ Enrique Fanjul, “Afrontar la crisis: el sector exterior (nuevamente) como motor de la recuperación de la economía española”, en Blog Elcano, Real Instituto Elcano, 16/04/2020, p. 3, disponible en https://blog.realinstitutoelcano.org/afrontar-la-crisis-el-sector-exterior-nuevamente-como-motor-dela-recuperacion-de-la-economia-espanola/, fecha de consulta más reciente: 18/04/2020.

${ }^{66}$ Iliana Olivié y Manuel Gracia, op. cit., p.5.

${ }^{67}$ Andrés Ortega, op. cit.

68 Isabelle Méjean, en "Mantener el régimen de comercio abierto", Organización Mundial del Comercio, disponible en https://www.wto.org/spanish/tratop_s/covid19_s/covid19 quotes_s.htm, fecha de consulta más reciente: 18/04/2020.

${ }^{69}$ Krystal Hu, "Offshoring Goes Full Circle: Chinese Firms Shipping Out”, in CKGSB, 06/09/2017, disponible en https://knowledge.ckgsb.edu.cn/2017/09/06/manufacturing/offshoring-full-circlechinese-firms/, fecha de consulta más reciente: 04/06/2020. 
por contradictorio que parezca, gracias a esta tendencia, se abre una posibilidad de recuperación económica para la UE, sobre todo para las regiones menos industrializadas. En situaciones de crisis, una actitud idónea, si bien compleja, consiste en la búsqueda de oportunidades. Por lo tanto, una actividad alternativa a desarrollar sería la industria, con el objetivo de exportar.

A largo plazo, la UE se plantea el reshoring de productos sanitarios esenciales, por medio de un protocolo que permita la elaboración de determinados materiales y equipos en situaciones de urgencia ${ }^{70}$.

Hay autores que mantienen que sería recomendable repensar la política industrial de la UE, con el objetivo de relocalizar las industrias europeas ${ }^{71}$.

Revisar la globalización podría tener efectos positivos en cuanto a mejorar la independencia europea respecto de China, especialmente en sectores estratégicos, pero el coste sería un aspecto no tan positivo.

Muchas empresas han percibido los riesgos de la excesiva interdependencia, y pretenden reprimirla. A este respecto, recientemente, el Bank of America ha emitido un informe, en cuanto a que el $80 \%$ de las multinacionales investigadas pretenden relocalizar parte de su producción. Sin embargo, no se precisa qué parte de la misma retornaría al país de origen. El virus producirá un mayor énfasis nacional o regional respecto de la producción, incluido el ámbito de los suministros médicos ${ }^{72}$. Aparentemente, va a disminuir la globalización física y se va a desarrollar la globalización digital ${ }^{73}$. Precisamente esta cuestión está directamente relacionada con el referido tráfico de datos, y con la soberanía, en este caso, específicamente, la digital.

En este aspecto incide especialmente el hecho de que la cantidad y valor del flujo de datos entre países aumenta, y este año crecerá aún más, sin resultar perjudicado por la COVID-19. De la misma manera que los productos manufacturados han sido el objeto de la anterior época de globalización, los datos serán el alma de la próxima. En vez de enterrar la globalización, la COVID va a acelerarla. La COVID ha dificultado el tráfico de mercancías, pero para nada ha afectado al tráfico de datos ${ }^{74}$.

Desde la COVID-19, ya se han producido varios notorios casos de reshoring. Pero no se trata de reshoring de regreso de China y otros países extracomunitarios a los que se realizó previamente el offshoring, sino que se

\footnotetext{
${ }^{70}$ Charles Powell, Ignacio Molina y José Pablo Martínez (coords.), op. cit., p. 31.

71 Ignacio Fuente Cobo, "El mundo después de la pandemia: el nuevo orden no será chino", en Documento Opinión, 33/2020, 21/04 (2020), p.8, disponible en http://www.ieee.es/Galerias/ fichero/docs opinion/2020/DIEEEO33 2020IGNFUE_mundo.pdf, fecha de consulta más reciente: 09/06/2020.

${ }^{72}$ Andrés Ortega, op. cit.

73 Andrés Ortega, op. cit.

74 Chris Miller, "Will COVID-19 Sink Globalization?", in Foreign Policy Research Institute, disponible en https:/www.fpri.org/article/2020/04/will-covid-19-sink-globalization/, fecha de consulta más reciente: 04/06/2020.
} 
trata de empresas de Francia, EEUU o Alemania que instalaron sus centros productivos en países como España, y ahora, ante la crisis provocada por la pandemia, regresan a sus países de origen. Son los casos, particularmente, de Ford, Nissan, Alcoa y Mercedes ${ }^{75}$. Sin embargo, el reshoring desde Asia a Occidente no se está produciendo en masa, sino acotado a sectores estratégicos, como las nuevas tecnologías ${ }^{76}$.

De momento, uno de los sectores de mayor valor estratégico cara a la pandemia es la fabricación de material sanitario, como es el caso de respiradores, test, mascarillas $\mathrm{y}$, en general, todo lo necesario en la protección contra el coronavirus. Puede ser un buen despegue para algunas maltrechas economías europeas. En este sentido, el Parlamento Europeo, en una Propuesta de Resolución:

[D]estaca que el sector médico y farmacéutico es fundamental para luchar contra el coronavirus; señala que este sector depende en gran medida del correcto funcionamiento de las cadenas mundiales de suministro y se enfrenta a dificultades de resultas del aumento del proteccionismo y las respuestas descoordinadas; pide la adhesión mundial a la iniciativa farmacéutica «cero por cero» de la OMC; considera fundamental que la Unión Europea recupere la soberanía tecnológica en el desarrollo y la producción de medicamentos esenciales, productos sanitarios y equipos de protección individual; subraya la necesidad de atraer nuevas inversiones en el sector médico de la Unión, desarrollar una estrategia de la Unión para la relocalización de la producción de suministros médicos estratégicos o, alternativamente, encontrar rápidamente formas de diversificar nuestras fuentes de importación para garantizar la fluidez de los intercambios comerciales y contribuir a crear reservas estratégicas y material rodante de equipos médicos ${ }^{77}$;

\footnotetext{
${ }^{75}$ Economía de Mallorca, “'Jueves negro' para la industria española”, 28/05/2020, disponible en http://economiademallorca.com/art/26045/jueves-negro-para-la-industria-espanola, fecha de consulta más reciente: 20/06/2020.

${ }^{76}$ Esteban Actis y Julieta Zelicovich, "El ritmo Básico de Reproducción del COVID-19 [sic] en la transformación del Sistema Internacional", [en Anabella Estella Busso, coord..: Relaciones Internacionales en tiempos de pandemia, Rosario, Edición para Centro de Investigaciones en Política y Economía Internacional, 2020], p. 25, disponible en https://d1wqtxts1xzle7.cloudfront. net/63634413/Busso_A. - C CIPEI_-RRII_en tiempos_de pandemia20200615-19737-hw81gr. pdf? $1592232769=$ \&response-content-disposition $=$ inline $\% 3 \mathrm{~B}+$ filename $\% 3 \mathrm{DEl}$ Ritmo Basico de Reproduccion del COVI.pdf\&Expires=1593955937\&Signature=JKRMooIaqq9-pBRMEQXtVLH hE4cey N0TvSZBIIONelXdJA2tfZbfar7doSorZLWdPRjWusgI-QtJeunwBy8N $\sim$ SoKbFknzrKvqoJ8 T38cxB8amLaQL8npwlFGYuFPg2HU2yARJUdTjicWlVmFmm-20x-ffCd4vK-YENfAdpZIyurxrG zZOOUCM6j1u9igf4AUfCUVKvpjLzjQFFK7Vhn2FIXR7xTaWDj6s2MkHgQvnxPJQACVM JVf e2xcyimWPWCo72CmSVKzmaAT2zmkajFXikLmKtH7Zy-chCnO3DDeyljF0tIjKqUXnPnU4TAC bSgs7u8hPE2HghB9qkx6f0JA \&Key-Pair-Id=APKAJLOHF5GGSLRBV4ZA\#page=95, fecha de consulta más reciente: 09/07/2020.

${ }_{77}$ Parlamento Europeo, Propuesta de Resolución, Documento de sesión B9-0149/2020, 14.4.2020, p. 21, disponible en https://www.europarl.europa.eu/doceo/document/B-9-2020-0149_ES.pdf, fecha de consulta más reciente: 04/06/2020.
} 
Se trata, en definitiva, de recuperar la soberanía tecnológica europea sobre sectores estratégicos, como por ejemplo, el sector de los mencionados suministros sanitarios. Pero, además, aparece en la mencionada Propuesta de Resolución una crítica a las respuestas descoordinadas.

Es interesante observar el caso de Inditex, líder mundial de logística "design-to-store". Inditex afirma: "E1 54\% de nuestras fábricas se sitúan en proximidad a nuestra sede central en Arteixo (A Coruña, España)"78.

Debido a la magnitud de la crisis, el apoyo público al sector privado parece que va a resultar imprescindible cara a la recuperación ${ }^{79}$.

\subsection{Nearshoring}

El nearshoring consiste en la localización cercana. En cuanto a un posible nearshoring a América, es cierto que está más cerca de la UE que China, pero quizá no lo suficiente. En los EEUU los costes de producción son más altos que en China, aunque hay quien mantiene que hay intangibles y tendencias a favor de EEUU ${ }^{80}$. Otra opción es Turquía, país con duraderas relaciones con Alemania. Concretamente, para hacernos idea de la distancia, un vuelo BerlínEstambul dura en torno a 2 horas ${ }^{81}$. Otras posibilidades de nearshoring (en cuanto a la cercanía) serían Ucrania, Bielorrusia o incluso la misma Rusia. Aunque es cierto que esta opción está más cercana de la Europa central y oriental que América, sin embargo, hay un escollo para el desarrollo de esta opción: las históricas suspicacias.

Una ventaja de esta opción es que los husos horarios entre las localizaciones de la empresa se superponen, lo que simplifica la colaboración entre los distintos equipos de la empresa ${ }^{82}$.

En cuanto a Europa occidental y del sur, ciertamente el territorio más cercano es África. En principio, la República Surafricana (más alejado de la UE que los EEUU) es el país más desarrollado dentro del continente. Quedaría por cotejar la posible opción que significarían los países del norte de África. Habría que compensar la diferencia de tecnificación, pero con menores costes de transporte, respecto de China.

\footnotetext{
78 Inditex-Proveedores, disponible en https://www.inditex.com/es/quienes-somos/inditex-en-elmundo\#continent/000, fecha de consulta más reciente: 07/06/2020.

${ }^{79}$ Iliana Olivié y Manuel Gracia, op. cit., p. 7.

${ }^{80}$ Integrated Systems Design, Comparing Manufacturing Costs: USA vs China, disponible en https://www.isddd.com/articles/comparing-manufacturing-costs-usa-vs-china/, fecha de consulta más reciente: $22 / 04 / 2020$.

${ }^{81}$ Calculadora de distancias entfernungsrechnernet, disponible en https://www.entfernungsrechner. net/es/distance/city/2950159/city/745044, fecha de consulta más reciente: 23/04/2020.

${ }^{82}$ Vladimir Fedak, "5 Benefits of Offshoring, Nearshoring \& Outsourcing for EU businesses", 20/07/2019, disponible en https://medium.com/@FedakV/5-benefits-of-offshoring-nearshoringoutsourcing-for-eu-businesses-39e723bf524c, fecha de consulta más reciente: 14/07/2020.
} 
Como reflexión resumen de las tres mencionadas opciones de localización industrial, decir que nos encontramos ante una encrucijada. Las opciones tienen distintos motivos. El offshoring pretende reducir los costes de producción, para lo que, en su día, se trasladó la producción a lugares lejanos, con el efecto del cierre de industrias locales y la destrucción de empleo. El reshoring puede evitar la dependencia de suministradores lejanos, debido al peligro de desabastecimiento en casos como la COVID-19. Es evidente que en la situación actual y venidera, con aumento de las cifras de paro, va a ser tentadora una opción como la relocalización. Se puede pretender crear empleo de esta forma, con el requisito de la competitividad. Esta afirmación tendría una excepción, que serían las industrias estratégicas, ya que, por sus peculiaridades, no se someten solo a criterios de competitividad.

Toda relocalización no competitiva, a la larga, incrementará las asimetrías. Pero lo mismo ocurrirá con la deslocalización competitiva. En definitiva, la clave es la competitividad, que redunda en beneficio de las empresas y también de los Estados, pero que también depende de un elemento esencial: la mano de obra. En este punto, va a resultar determinante el nivel de capacitación y especialización de los operarios.

Se puede acometer el abandono del offshoring, que en definitiva también implica el retroceso de la globalización, es decir, el impulso de la desglobalización. Pero dicha opción implicaría el aumento de los precios que hoy paga el consumidor, y que repercutirían sobre el mismo, perjudicando su capacidad de compra.

En cuanto al nearshoring, sus motivaciones son las mismas que el offshoring, pero reduciendo los costes de transporte, y mejorando las posibilidades de mantener el suministro en caso de catástrofe. Es decir, que esta opción combina casi tanta cercanía como el reshoring, con los bajos costes del offshoring. Pero aun así, el nearshoring tiene dos inconvenientes: ni favorece a la comunidad local del correspondiente Estado miembro de la UE en cuanto a la creación de empleo, como el reshoring, ni posee la misma competitividad de los hasta ahora suministradores en offshoring. Sin embargo, hasta el momento, parece que esta opción sería factible para industrias que no requieren de una gran precisión, que necesitan de menos tecnificación, debido al diferencial tecnológico entre los actuales proveedores y las regiones próximas a la UE. Sin embargo, esta realidad también está cambiando, como es el caso de Turquía, que se ha convertido en potencia mundial en la fabricación de drones. 


\section{Conclusiones}

Las consecuencias de la COVID-19 no se ciñen exclusivamente a la pandemia, sino que la misma está sirviendo de banco de pruebas de las capacidades de los actores internacionales. El ámbito estrictamente sanitario es, sin lugar a dudas, donde se producen las más graves consecuencias de la pandemia. Sin embargo, también está teniendo palpables consecuencias económicas, sociales e incluso políticas. Además, es probable que la actual coyuntura precipite la adopción de nuevas iniciativas, que habrán de verse reflejadas en las instituciones de la UE. Además, esta podría ser la ocasión para que la UE se consolide. En caso contrario, la Unión se podría ver afectada en su propia concepción.

Tras la pandemia, surge el temor al desabastecimiento, perjudicado por la enorme distancia entre el país suministrador y los países destino de su producción. Por ello, China, al igual que otros proveedores emergentes, probablemente incrementará su competitividad, con el objetivo de evitar la relocalización de las industrias.

En cuanto a cuál será la tendencia dominante de las tres expuestas (offshoring, reshoring, nearshoring) es probable que el resultado final sea una combinación de al menos dos de estas opciones. Hay empresas que combinan los tres sistemas. El offshoring, base para la globalización, no parece que vaya a desparecer radicalmente en la relación UE-China, ya que de momento no se vislumbra una alternativa convincente. Por lo que se refiere al reshoring, podría significar el lanzamiento de nuevas regiones industriales en la UE con posibilidades de éxito, al menos para los sectores estratégicos. Será un proyecto arduo, pero que abre interesantes oportunidades de desarrollo para las economías de los Estados miembro.

La cuestión va a ser no solo si la UE cambia de proveedor, sino también en qué situación económica va a quedar la UE como destino de las exportaciones chinas. Esta será, claramente, una de las consecuencias de la debacle económica que, previsiblemente, se cierne sobre la vieja Europa. Es decir, no solo se trata de si la UE va a querer cambiar de socio comercial prioritario, abandonando a China, sino también de, habida cuenta de la citada situación económica, hasta qué punto China va a prestar especial atención comercial a Europa.

El conjunto de lo antedicho nos lleva a concluir que, tras la COVID-19, la asimetría entre ambas partes al menos no disminuirá. Es más, es probable que las relaciones UE-China sean aún más asimétricas, a favor de China. A lo largo de la historia de las relaciones entre ambas partes, como hemos señalado, se han sucedido épocas en las que las asimetrías, alternativamente, han favorecido a una y a otra parte. Por lo tanto, no se puede decir que las actuales asimetrías vayan a ser definitivas. Las asimetrías son inevitables en 
las relaciones internacionales, pero es deseable que no sean abrumadoras. Se reducen por medio del aumento de la cohesión y competitividad de la parte desfavorecida, en este caso la UE. De esta manera, las relaciones serán más duraderas y menos conflictivas.

Además, no se ha de olvidar que también la cohesión social dentro de la UE y de cada país es prioritaria para la institución europea. 


\section{Referencias bibliográficas:}

Actis, E., y Zelicovich, J., "El ritmo Básico de Reproducción del COVID-19 [sic] en la transformación del Sistema Internacional", [en Anabella Estella Busso, coord..: Relaciones Internacionales en tiempos de pandemia Rosario, 2020], disponible en https://rephip.unr.edu.ar/bitstream/ handle $/ 2133 / 18304 /$ Busso $\% 20-\% 20$ RRII $\% 20$ en $\% 20$ tiempos $\% 20 \mathrm{de} \% 20$ pandemia.pdf? sequence $=3 \&$ isAllowed $=\mathrm{y}$, fecha de consulta más reciente: 09/07/2020.

Adams, J. y Sargent, T., "Curriculum Transformation in China: Trends In Student Perceptions of Classroom Practice and Engagement", Gansu Survey of Children and Families Papers, pp. 19-20, available at http:// repository.upenn.edu/cgi/viewcontent.cgi? article $=1032 \&$ context $=$ gansu papers, fecha de consulta más reciente: 17/07/2020.

Armesilla, S., "De la Peste Negra al Coronavirus: el Resurgimiento de China en la Segunda Guerra Fría", en La Razón Comunista, 11/06/2020, p. 8, disponible en https:/www.larazoncomunista.com/post/4-2-de-la-pestenegra-al-coronavirus-el-resurgimiento-de-china-en-la-segunda-guerrafr\%C3\%ADa, fecha de consulta más reciente: 12/07/2020.

Benedicto, M. A., "Los retos de Europa y su futuro tras la pandemia de la COVID-19", en Documento de Opinión 72 (2020), 26/05/2020, pp. 1-14, disponible en http://www.ieee.es/Galerias/fichero/docs_opinion/2020/ DIEEEO72 2020MIGBEN_retosEU.pdf, fecha de consulta más reciente: $09 / 06 / 2020$.

Borrell, J., "Cuatro prioridades para una estrategia global contra la pandemia", en ICEI Papers COVID-19, No 13, 07/04/2020, disponible en https:// www.ucm.es/icei/file/iceipapercovid13, fecha de consulta más reciente: $12 / 07 / 2020$.

Cabestan, J.-P., "China's Battle with Coronavirus: Possible Geopolitical Gains and Real Challenges", en Al Jazeera Centre for Studies Report, 19/04/ (2020), pp. 1-21, disponible en https://studies.aljazeera.net/sites/default/ files/articles/documents/2020-04/China $\% \mathrm{E} 2 \% 80 \% 99 \mathrm{~s} \% 20 \mathrm{Battle} \% 20$ with $\% 20$ Coronavirus $\% 20$ Possible $\% 20$ Geopolitical $\% 20$ Gains $\% 20$ and\%20Real\%20Challenges.pdf, fecha de consulta más reciente: 03/06/2020.

Demertzis, M., Sapir, A., Tagliapietra, S. and Wolff, G. "An effective economic response to the coronavirus in Europe", en Policy Contribution 06 (2020), Bruegel, pp. 1-10, disponible en https://www.bruegel.org/2020/03/ economic-response-coronavirus/, fecha de consulta más reciente: $16 / 04 / 2020$. 
Esteban, M., "La crisis del coronavirus y el estatus internacional de China: cuando la geopolítica y la política doméstica no van de la mano", en Comentario Elcano 6 (2020), 18/03 (2020), pp. 1-4, disponible en http:// www.realinstitutoelcano.org/wps/portal/rielcano_es/contenido?WCM GLOBAL_CONTEXT=/elcano/elcano es/zonas es/comentario-estebancrisis-coronavirus-estatus-internacional-china-cuando-geopolitica-ypolitica-domestica-no-van-de-la-mano, fecha de consulta más reciente: 10/10/2020.

Esteban, M., "La evolución de la política exterior China”, en Araucaria, año 18, $n^{\circ} 35$ (2016), pp. 301-318, disponible en https://revistascientificas.us.es/ index.php/araucaria/article/view/2677, fecha de consulta más reciente: 01/06/2020.

Fanjul, E., "Afrontar la crisis: el sector exterior (nuevamente) como motor de la recuperación de la economía española”, en Blog Elcano, Real Instituto Elcano, 16/04 (2020), https://blog.realinstitutoelcano.org/afrontar-lacrisis-el-sector-exterior-nuevamente-como-motor-de-la-recuperacion-dela-economia-espanola/, visitado por última vez el 18/04/2020.

Fedak, V., "5 Benefits of Offshoring, Nearshoring \& Outsourcing for EU businesses", 20/07/2019, disponible en https://medium.com/@,FedakV/5benefits-of-offshoring-nearshoring-outsourcing-for-eu-businesses39e723bf524c, fecha de consulta más reciente: 14/07/2020.

Fernández Peláez, J. M., "China y Estados Unidos en el interregno por la sucesión imperial: ¿surgimiento de una nueva superpotencia o nuevo orden bipolar?”, en Academia, disponible en https:/www.academia.edu/43408396/ China y_Estados Unidos en el interregno por la sucesi $\% \mathrm{C} 3 \% \mathrm{~B} 3 \mathrm{n}$ imperial surgimiento de una nueva superpotencia o nuevo orden bipolar, fecha de consulta más reciente: 08/06/2020.

Fuente Cobo, I., "El mundo después de la pandemia: el nuevo orden no será chino", en Documento Opinión, 33/2020, 21/04 (2020), pp. 1-11, disponible en http://www.ieee.es/Galerias/fichero/docs_opinion/2020/ DIEEEO33 2020IGNFUE mundo.pdf, fecha de consulta más reciente: 09/06/2020.

García-Weil, A., "European Union-China: Two Asymmetrical Weltanschauungs about Human Rights. Remarks on the United States Concept of Human Rights", en TSN, 20/01 (2020), p. 3, disponible en http:// transatlanticstudiesnetwork.uma.es/?p=4053, fecha de consulta más reciente: $14 / 04 / 2020$.

García-Weil,A., "TheBeltandRoad Initiativeand the cohesion of theEuropeanUnion", en Revista de Estudios Europeos, No 74, julio-diciembre (2019), pp. 107-122, disponible en http://www.ree-uva.es/images/numeros/74/2019-74-107-137.pdf, fecha de consulta más reciente: 14/04/2020. 
Hackler, M., "Rapprochement amid readjustment: how China sees issues and trends in its changing relationship with the EU", en Asia Europe Journal, 28/05/2020, disponible en https://link.springer.com/content/pdf/10.1007/ s10308-020-00580-5.pdf, fecha de consulta más reciente: 03/06/2020.

$\mathrm{Hu}, \mathrm{K}$., "Offshoring Goes Full Circle: Chinese Firms Shipping Out", in CKGSB, 06/09/2017, disponible en https://knowledge.ckgsb.edu.cn/2017/09/06/ manufacturing/offshoring-full-circle-chinese-firms/, fecha de consulta más reciente: 04/06/2020.

Johansson, C. and Reischl, E., Offshoring to China-A case study of an SMEs offshoring to China, Baltic Business School, 2009, p. 105, disponible en http://www.diva-portal.org/smash/get/diva2:222631/FULLTEXT01. pdfElisabeth, fecha de consulta más reciente: 18/04/2020.

$\mathrm{Ku}$, J., "China's Definition of the 'Peaceful Settlement of International Disputes' Leaves Out International Adjudication", en Opinio Juris, available at http://opiniojuris.org/2013/10/15/obligation-seek-peacefulsettlement-international-disputes-include-international-adjudication/, fecha de consulta más reciente: 08/02/2017.

Llera, M., "El paradigma chino en el escenario global", en Araucaria, año 18, $\mathrm{n}^{\mathrm{o}} 35$, primer semestre (2016), pp. 249-274, disponible en https:// revistascientificas.us.es/index.php/araucaria/article/view/2799, fecha de consulta más reciente: 01/06/2020

Loyer, B. y Giblin, B., “QQué mundo geopolítico después de 2020?”, en Geopolitica(s). Revista de estudios sobre espacio y poder, 11, (2020), pp. 115-126, disponible en https://revistas.ucm.es/index.php/GEOP/article/ view/69250/4564456553387, fecha de consulta más reciente: 08/06/2020.

Mahbubani, K., "Has China Won? The Chinese Challenge to American Primacy", Source: Ambassadors Brief, disponible en https://mahbubani. net/2020/03/31/has-china-won-the-chinese-challenge-to-americanprimacy/, fecha de consulta má reciente: 06/07/2020.

Mahbubani, K., The New Asian Hemisphere: The Irresistible Shift of Global Power to the East, Washington, PublicAffairs, 2009.

McKibbin, W. y Fernando, R., "The Global Macroeconomic Impacts of COVID-19: Seven Scenarios", en CAMA Working Paper, 19 febrero (2020), p. 21, disponible en http://www.sensiblepolicy.com/download /2020/2020WorkingPapers/2020 19 CAMA COVID19 mcKibbin fernando 0.pdf, fecha de consulta más reciente: 05/06/2020.

Méjean, I., en "Mantener el régimen de comercio abierto", Organización Mundial del Comercio, disponible en https://www.wto.org/spanish/ tratop_s/covid19 s/covid19 quotes_s.htm, fecha de consulta más reciente: $18 / 04 / 2020$. 
Miller, C., "Will COVID-19 Sink Globalization?", en Foreign Policy Research Institute, disponible en https://www.fpri.org/article/2020/04/will-covid19-sink-globalization/, fecha de consulta más reciente: 04/06/2020.

National Health Commission of the People's Republic of China, "Timeline of China releasing information on COVID-19 and advancing international cooperation", 06/04/2020, disponible en http://en.nhc.gov.cn/202004/06/c 78861 5.htm, fecha de consulta más reciente: 07/06/2020.

Nye, J., "Soft Power", en Foreign Policy, No. 80, Otoño, 1990, pp. 153-171, p. 154, Publicado por: Washingtonpost. Newsweek Interactive, LLC, disponible en http://www.jstor.org/stable/1148580, fecha de consulta más reciente: 19/03/2017.

Oliva, C., "La política internacional china en los tiempos del COVID-19. Retos ante una coyuntura compleja", pp. 85-86, [en Busso, A. (coord.), Relaciones Internacionales en tiempos de pandemia, Rosario, Edición para Centro de Investigaciones en Política y Economía Internacional, 2020], disponible en http://rephip.unr.edu.ar/xmlui/bitstream/handle/2133/18304/Busso, $\% 20$ A.\%20-\%20CIPEI\%20-\%20RRII\%20en \%20tiempos $\% 20$ de $\% 20$ pandemia.pdf?sequence $=3$, fecha de consulta más reciente: 09/07/2020.

Olivié, I. y Gracia, M., “¿El fin de la globalización? Una reflexión sobre los efectos de la crisis del COVID-19 [SIC] desde el Índice Elcano de Presencia Global", en Real Instituto Elcano, ARI, 43 (2020), 14/04/2020, pp. 1-19, disponible en http://www.realinstitutoelcano.org/wps/portal/ rielcano_es/contenido?WCM_GLOBAL_CONTEXT=/elcano/elcano_es/ zonas es/ari43-2020-olivie-gracia-fin-de-la-globalizacion-reflexionefectos-crisis-covid-19-indice-ecano-de-presencia-global, fecha de consulta más reciente: 21/04/2020.

Ortega, A., "The Deglobalization Virus?" en The Globalist-Rethinking globalization, 18/03/2020, disponible en https://www.theglobalist.com/ coronavirus-covid19-pandemic-globalization-deglobalization-globalism/, fecha de consulta más reciente: 09/06/2020.

Pardo, V., "Offshoring, reshoring y nearshoring: Tres hipótesis para un nuevo orden productivo global post-COVID19”, en RANKIA, 07/04/2020, disponible en https://www.rankia.com/blog/finanzas-exoticas/4557267offshoring-reshoring-nearshoring-tres-hipotesis-para-nuevo-ordenproductivo-global-post-covid19, fecha de consulta más reciente: 16/04/2020.

Powell, C., Molina, I. y Martínez, J. P. (coords.), "Una reflexión estratégica en contexto europeo e internacional", en Real Instituto Elcano, Junio 2020, disponible en https://especiales.realinstitutoelcano.org/coronavirus/, fecha de consulta más reciente: 08/07/2020. 
Ramonet, I., "Ante lo desconocido - La pandemia y el sistema-mundo", en Le Monde Diplomatique, 04/05/2020, p. 28, disponible en https://www. eldiplo.org/wp-content/uploads/2020/04/Ramonet-pandemia.pdf, fecha de consulta más reciente: 13/07/2020.

Roldán Barbero, J., "Reflexiones de un internacionalista sobre la pandemia./4. Los derechos individuales y los derechos (y obligaciones) estatales", en Aquiescencia, 26/06/2020, disponible en https://aquiescencia. net/2020/06/26/reflexiones-de-un-internacionalista-sobre-la-pandemia-4los-derechos-individuales-y-los-derechos-y-obligaciones-estatales-porjavier-roldan-barbero/, fecha de consulta más reciente: 09/07/2020.

Rosado, J., "Retos y desafíos de la nueva normalidad", en El FinancieroEconomía, Mercados y Negocios en alianza con Bloomberg, 28/05/2020, disponible en https://www.elfinanciero.com.mx/opinion/colaboradorinvitado/retos-y-desafios-de-la-nueva-normalidad, fecha de consulta más reciente: 01/06/2020.

Salvoni, N., "Covid-19 y política internacional:¿ estamos ante un cambio de paradigma?", en Economía del Desarrollo, Universidad Nacional de Quilmes, disponible en http://economia.unq.edu.ar/la-influencia-de-covid19-en-la-politica-internacional-estamos-ante-un-cambio-de-paradigma/, fecha de consulta más reciente: 01/06/2020.

Schmalz, S., "Der Corona-Crash in China", en PROKLA 199, 2/06, (2020), pp. 355-362, disponible en https://doi.org/10.32387/prokla.v50i199.1878, fecha de consulta más reciente: 08/06/2020.

Seaman, J., "Introduction: China as partner, competitor and rival amid Covid-19", [en John Seaman, coord.: Covid-19 and Europe-China Relations - A country-level analysis, European Think-tank Network on China (ETNC) Special Report - 29/04 (2020)], pp. 5-10, disponible en http:// www.realinstitutoelcano.org/wps/portal/rielcano en/publication?WCM GLOBAL CONTEXT=/elcano/elcano in/publications/etnc-specialreport-covid-19-europe-china-relations-2020, fecha de consulta más reciente: $17 / 06 / 2020$.

Starr, F. and Cornell, S., "The EU and Central Asia: Developing Transport and Trade", en Analytical Articles, December 10th, 2015, disponible en https:// www.cacianalyst.org/publications/analytical-articles/item/13313-the-euand-central-asia-developing-transport-and-trade.html, fecha de consulta más reciente: 13/04/2020.

Steinberg, F., "Coronavirus: amenaza económica, respuesta política e implicaciones", en Real Instituto Elcano ARI 22 (2020), 12/04/2020, pp. 1-7, disponible en http://www.realinstitutoelcano.org/wps/portal/ rielcano_es/contenido?WCM_GLOBAL_CONTEXT=/elcano/elcano es/zonas es/ari22-2020-steinberg-coronavirus-amenaza-economica- 
respuesta-politica-e-implicaciones, fecha de consulta más reciente: 13/04/2020.

Yin, J., et al, "Entanglement-based secure quantum cryptography over 1,120 kilometres", en Nature, 15/06/2020, (2020). disponible en https://www. nature.com/articles/s41586-020-2401-y, fecha de consulta más reciente: 18/06/2020.

Zibechi, R., "A las puertas de un nuevo orden mundial" [en Néstor Borri, coord.: Sopa de Wuhan-Pensamiento contemporáneo en tiempos de pandemias, Editorial ASPO, 2020], pp. 115-116, disponible en https:// repositorio.uca.edu.ar/handle/123456789/10038, fecha de consulta más reciente: 12/07/2020. 